\title{
The Modern Way to Menstruate in Latin America: Consolidation and Fractures in the Twenty-First Century
}

\author{
Eugenia Tarzibachi
}

\section{Introduction: The Modern (and American) Way to Menstruate as a Feminine Disciplinary Practice}

The so-called "feminine care" or "Femcare" industry that designed and commercialized disposable pads and tampons during the twentieth century changed the experience of the menstrual body in many (but not all) countries of the world. A new disciplinary practice, ${ }^{1}$ which Lara Freidenfelds has called "the modern way to menstruate," took hold as the dominant form of femininity ${ }^{2}$ among bio-women ${ }^{3}$ (2009). It implied more than just a new way to do something about menstrual blood every month; these products conceal it efficiently and get rid of the associated burden of the menstrual experience in a more pragmatic way. The disposability of the products became a metaphor for the disposability of the menstrual "crisis" - that is, exposed, public menstruation risked by a barbaric, uncontrollable version of women's bodies. This new way to menstruate also implied a new way to think and talk, spreading the knowledge accumulated by the modern bio-medical discourse about menstruation (Freidenfelds 2009; Brumberg 1997).

One critical component of the modern way to menstruate was the replacement of homemade menstrual management products made of reusable pieces of towels, cloth, and/or cotton, which were portrayed by the Femcare industry as outdated. The new "feminine protection" products were marketed as a modern way to manage the hygienic "problem" of women's bodies. The products were meant to liberate bio-women from a natural aspect of their biology that had been framed as a monthly problem. From a subjective perspective, women felt liberated by the pads and tampons that helped them 
pass as non-menstruators, but the industry perpetuated and capitalized on the shame and disgust that continued to be associated with their menstrual bodies, albeit "under wraps" (Vostral 2008; Kissling 2006). Menstrual stigma seemed to disappear when the experience of the "menstrual crisis" was significantly reduced, but the shame women felt about their menstrual bodies was perpetuated subtly. The corporeal ideal of a (masculine) non-menstrual body was never problematized; on the contrary, when the menstrual body could be concealed in a more efficient way the ideal was reproduced and continued to nurture menstrual stigma. Therefore, the idea that women were liberated by pads and tampons is paradoxical, since they were now compelled to conceal the menstrual blood through standardized technologies and, in doing so, became somewhat alienated from their periods.

From a Latin-American perspective, this modern way to menstruate was also American, since most of the companies that opened and consolidated the "Femcare" market in Latin America originated in the United States: Johnson \& Johnson, Kimberly-Clark, and Procter \& Gamble (all now transnational conglomerates). My in-depth study of the experiences of Argentinean women who lived in big cities like Buenos Aires when these products were first available shows that Argentineans who used these products felt that they were entering modernity. For them, it represented not only social status in general, but also alignment with the most developed societies of the world.

In the countries of Las Americas, the proliferation and dissemination of disposable menstrual management technologies occurred at different times, depending on the markets' geography, social class, race, and age. Beyond these particulars, the overall impact of this process can be seen in the global, multimillion-dollar market consolidated by these companies. The major Femcare companies continue to expand, testing new rhetoric that in some cases deeply challenges menstrual stigma. Simultaneously, they are facing competition from new menstrual management technologies, such as reusable products or contraceptives that suppress menstrual bleeding (Hasson 2016; Sanabria 2016).

This chapter, based on some of the main findings of my doctoral and postdoctoral research conducted from 2009 to 2018 , describes and analyzes how the dissemination and proliferation of disposable pads and tampons unfolded in the region, and how this process reinscribed traditional narratives about gender. I will focus on a counterpoint between the United States and Argentina as paradigmatic of what happened in the rest of Latin America (Tarzibachi 2017). I will also summarize some of the current initiatives that purport to break down menstrual stigma, as well as look at "new" discourses about other menstrual management technologies that are negotiating their own position alongside the disposable pads and tampons that remain the dominant way to menstruate. 


\section{The Early Femcare Industry in Las Americas: Origins and Dissemination of Pads and Tampons in the United States and Argentina}

The first disposable pad in the United States-Lyster Towels, by Johnson \& Johnson-actually appeared at the end of the nineteenth century, but it was a commercial failure. It was not until after World War I that Kimberly-Clark found a way to successfully monetize women's menstruation. Numerous factors contributed to their success, including growing industrialization, a deep menstrual taboo, and a desire to "civilize" bodies that was nourished by the social hygiene movement. But above all, the invention of feminine pads was driven by economic benefit, a way to capitalize on an invention from World War I (Vostral 2008). The history of the pad's emergence is an example of how women's reproductive bodies were placed at the service of maximizing corporate profits and how a product created for wartime was adapted for civilian use in the postwar period.

Ever since the American Civil War and emancipation, cotton prices had risen steadily. In 1915, Kimberly-Clark began to manufacture cellucotton-a cheaper, more absorbent substitute for cotton-to sell to hospitals as surgical dressings (Heinrich and Batchelor 2004; Sahlberg 2011). In 1917, when the United States entered World War I, the company began selling cellucotton to the North American Navy and the Red Cross; it had contracts to provide some 375 tons to each and opened new factories to produce these immense quantities. Then the signing of the armistice in November 1918 canceled the contracts and left the factories idle (Heinrich and Batchelor 2004, 44). The company decided to optimize both assets by reconfiguring the product and creating feminine hygiene pads (Sahlberg 2011, 34). According to Heinrich and Batchelor, the potential waste was perhaps "the only factor that could persuade the businessmen of those decades to think about menstrual hygiene and precipitated the search for alternative uses for the cellulose product that led to the introduction of Kotex" $(2004,2)$. Kimberly-Clark's institutional narrative says that the idea came from The American Fund for French Wounded, which "received letters from the nurses of the North American Navy mentioning having improvised hygienic towels with cellucotton surgical gauze" (48).

The company's aversion to loss was so motivating that it confronted social taboos, albeit through a marketing strategy of extreme discretion. In 1920 the company created a subsidiary, Cellucotton Products Company, to launch the Kotex brand, thereby shielding the Kimberly-Clark name from association with menstruation. Ads did not include the words "sanitary" or "sanitary towel," so women simply had to ask retailers for the neutral-sounding "Kotex," a brand name that suggested cellucotton, cotton, and a "cotton-like-texture" (Heinrich and Batchelor 2004, 48). In 1921, the first Kotex ad was published in Ladies' Home Journal. This first ad did not refer to 
feminine hygiene; rather, it was linked to patriotism, war, and science, to connote the technological protection of wounded (vulnerable) bodies. Following the introduction of Kotex, Johnson \& Johnson quickly launched Modess to compete with Kimberly-Clark and many other minor brands.

Tampons were introduced in the United States in the 1930s, about a decade after pads. While there are records of many brands of tampons-mostly with applicators-Tampax dominated the market. The applicators may have removed some concerns women had with tampons, such as touching their genitals and protecting the hymen. Acceptance was also enhanced by ad campaigns that normalized menstruation and encouraged the use of tampons to facilitate women's work outside the home during World War II. The widespread acceptance of tampon use in the United States might also be attributed to a pragmatic culture and strong feminist movement.

In Argentina, the first generation of disposable pads was launched by the end of the 1930s; tampons arrived in the late 1960s through the 1970s, but they have not achieved the same level of acceptance as in the United States. Modess from Johnson \& Johnson was the main brand of the first generation of pads. Kotex arrived in Argentina around 2010, almost a century after its appearance in the American market. Johnson \& Johnson's o.b. tampons were launched almost simultaneously in the United States and Argentina (around 1975); they are the generic name of tampons in Argentina, although today there are many other brands in the local market. While pads were advertised in Argentina just one decade after the American market, tampons lagged by three to four decades. Both cultural and political factors contributed to this lag. One reason for this is that the tampon required women to be willing to touch their own genitalia and have some knowledge about it. In this highly conservative society, where Catholic influence on the culture and the interruption of a dictatorship slowed the development of feminist movements, these requirements were often missing.

\section{Menstrual Bodies, Management, and Meanings: The Sociocultural Component of the Transition from Reusable Rags to Manufactured and Disposable Products}

This section provides a comparison between existing research, which details when and under what circumstances women adopted changing menstrual technologies in the United States, with my own research on this transition in Argentina. I interviewed women from the city and province of Buenos Aires who were young in the 1970s-those who lived the transition between the reusable and disposable products. ${ }^{4}$ For the most part, American and Argentinian women adopted disposable pads first and tampons later-and only some accepted tampons. This happened differently in each country and depended largely on women's social class. Also, while the use of pads was embraced without controversy in the United States 
(around the 1950s) and in Argentina (around the 1960s and 1970s in urban sectors), the same was not true for tampons.

\section{Reusable Cloth}

In the United States, studies indicate that, before the appearance of disposable pads, most women used homemade cloths that they boiled and reused (Freidenfelds 2009). In the nineteenth century, they made their own pads, folding and sewing cotton, gauze, or rags that they fastened with hooks to their underwear. Some wore petticoats and rubber aprons to avoid stains on clothing (Vostral 2008, 243). In Argentina, the women interviewed indicated that at the time of their menarche (sometime between 1950 and the beginning of 1970) they, like their mothers, used leftover cuts of clothes, sheets, T-shirts, and towels, usually white. Some mentioned that those "rags" or "cloths" could also be purchased already made in the pharmacy and then washed and reused. They washed them by hand with cold water and white soap until the blood stain was gone. Some women from low-income sectors went into much more detail about the washing. A few mentioned that they boiled the cloth if the stain did not come out. Noemí ( 55 years old), who grew up in a town in Santiago del Estero and came to Buenos Aires in the mid-1970s, said:

I remember that my mother gave us rags. We could not throw the rags [away]. We had to wash them and hang them and you can't imagine the shame we felt.... We first took the blood out of the rags with cold water, then put them in white soap, rinsed them, and finally put them under the sun. And they turned whiteeeee. And if the blood did not come out, if the rags were stained, they were boiled in a pot [over a fire] that we always had at that time ... exclusively for that. Like the shoes, when we washed them, we put chalk on them.

Many women mentioned that they tried to avoid using bleach, since it irritated the vulva and if you used it, "you went all bald." They were also emphatic about the need to hide the materials, especially from men, both during the laundering process and while they were being worn. For a better grip, some wore girdles, hooks, or special belts.

\section{Disposable Pads}

By between 1940 and 1950, women in the United States overwhelmingly used disposable pads. By that time, using rags had become a symbol of poverty and disposable pads became a necessity, even for those who did not yet belong to the middle class. Work by Lara Freidenfelds (2009) shows that, for poor and working-class white Americans, African Americans, and daughters of immigrants, disposable pads constituted a way of becoming Americanized and belonging to the middle class to which they aspired. Among adolescents 
of working-class families, especially immigrants, disposable pads were a way of assimilating, of leaving behind their mothers' Old World culture and becoming modern Americans (Brumberg 1997). Brumberg's research shows that in the 1930s and 1940s, the daughters of immigrants still used "homemade protectors," and in the Italian community, for example, mothers did not encourage their daughters to change the cloths frequently, not only because of the cost but because a bloody pad meant fertility $(1997,44)$. Learning about menstruation:

was less private and more social in the working-class, because poor girls had more opportunities to mix with women of different ages in work, the kitchen, or in common bathrooms ..... For the daughters of immigrants, it was extremely important to be 'scientific' and 'up to date' on issues related to menstruation and appearance. Girls born in America . . . understood, before their mothers or grandmothers, that there was a North American way of menstruating, that it required participation in the broader consumer society. (Brumberg 1997, 45)

Among the Argentinian middle-class women interviewed-mostly daughters of European immigrants who lived all their lives in the province of Buenos Aires or the federal capital - the adoption of disposable pads occurred throughout the 1960s; as in America, it was a way of belonging to the middle class (Cosse 2014). As young women, they had to question the menstrual management practices that their mothers had taught them, and they came to regard women who still washed "rags" as "barbaric" or poor. This was reinforced by Johnson \& Johnson's educational material, "Learn to be a woman," which circulated in schools in the Federal Capital in the late 1960s. The material concluded with a clear description of what it took to be a "modern woman": "You will not really be a modern girl if you do not use MODESS for your intimate protection. FREE YOURSELF AND LIVE."

In the Argentinian interviews, discussion of the move from washable to disposable products often prompted laughter as well as pejorative value judgments regarding the practices of their mothers. It also exposed a dimension of social snobbery. The middle-class women remembered Modess as their first disposable pads and used the term generically; by contrast, none of the women from lower-income sectors recalled their first brand. Those from lower-income sectors-almost all of whom were born in the northern provinces or in countries bordering Argentina and later migrated to Buenos Aires or the federal capital-associated the use of disposable pads with their relocation; this was where they became aware of the products, realized these pads were necessary to become "urbanized," and found them economically accessible. They all had to work, and disposable pads simplified that. However, this consumption was an extravagance for some, even long after the 1970s. They said that the pads "that were thrown" were more hygienic, but they used them only to leave their homes because they were "thrown silver." Carina 
(65 years old), for example, came from Paraguay in 1974 and started using disposable pads when she arrived in Buenos Aires, but because they were expensive she alternated with the cloths-a habit she maintained until menopause. This alternating pattern was also seen with disposable baby diapers in the 1980s: Moms used them only to take the baby to the doctor. Otherwise, they were viewed as an extravagance.

\section{Tampons}

Tampons were first used in the United States in the 1940s by women who worked outside the home; ballerinas and athletes were early adopters (Vostral 2008). By the time use became widespread, between 1960 and 1970, most versions included applicators (Freidenfelds 2009). With the sexual revolution, tampons were especially attractive to young American women. Many of the women interviewed by Freidenfelds, born between the late 1930s and 1950s, also first tried them in the 1960s.

In the United States, there was extensive medical discussion of tampons. Beginning with their introduction in the late 1930s, there was concern in the medical community and among women about tampons' effectiveness, safety, and sexual implications. Concerns about sexuality centered on the potential rupture of the hymen, autoeroticism, and promiscuity-all based on the assumption that the tampon imitated heterosexual intercourse (Vostral 2008; Freidenfelds 2009). Kimberly-Clark educational material from as early as 1952 tried to dispel these concerns, stating that the tampon was smaller than the opening to the hymen and therefore safe for even the youngest menstruator. They also attempted to educate women about the safety of submerging in water. The issue of tampon use prompting masturbation was simply ignored (Freidenfelds 2009, 175). By the 1960s tampons were less controversial and ads and educational materials encouraged adolescents to use tampons. Medical discussion dissipated, until it resumed in the late 1970s and early 1980s following the deaths of women from Toxic Shock Syndrome (TSS) (see Vostral, in this volume).

Brumberg (1997) examines the sexual implications of tampon use, taking into account the significance of the hymen as a symbol of purity, aptitude for marriage, class membership, moral standard, and object of family control. These concepts were already losing strength as gynecological exams became part of women's health care, and these exams were closely correlated with using tampons. Industry materials undertook work that could be called the "de-sexualization of the tampon," disseminating knowledge about the female genital tract, including the role of the clitoris and how tampons bypassed it completely (Brumberg 1997). Likewise, doctors steered mothers to more fact-based information about their daughters' bodies.

There were some factors of tampon adoption particular to the daughters of immigrants, African Americans, and the poorest white women, who 
had to cross borders of race, class, culture, and religion to test and use it (Freidenfelds 2009). In this sense, tampons were a culminating expression of the modern management of the menstrual body, an ideal that originated from and reflected the values of white, urban, and educated women of the American middle class of the early twentieth century (Freidenfelds 2009).

In Argentina, the 1960s and 1970s were a time that could be referred to as "authoritarian modernization." The strong conservative (Catholic) culture of those years, crossed by successive military coups, left a very narrow place for women. Some conservative women even judged a single woman's decency by whether or not she used tampons. While the tampon was a symbol of the modern woman who embraced new innovations, most of the Argentinian women I interviewed stated or implied that they didn't use tampons until after they were married, had their first sexual relationship, or had children. The preservation of virginity - which the tampon endangered in their imaginations-was a powerful social value in relation to the sexual morality that governed not only the social order but women themselves. It is important to note that, unlike in the United States, gynecologists in Argentina did not use speculums when examining young girls who had not had their first sexual relationship. According to medical articles published in Argentina (for example, Siemaszcko et al. 1980), this was true even in the 1980s, when doctors used ultrasound scans instead.

It was within this context that tampons began to gain acceptance among young, educated, middle-class women who saw what Isabella Cosse (2009) called the emergent prototype of the "liberated young woman." Most middle-class women and adolescents in the 1970s used tampons at least sometimes-to play sports, wear the tight-fitting jeans that had come into style, and especially to swim and sunbathe during the summer (Manzano $2009,2010)$. Although the issue of "internal use" remained an obstacle, this was mostly true among women from lower-income sectors, many of whom never even tried tampons. The boundaries of social class were significant: certainly economics was a large consideration, but symbolism factored in as well. Among these women, lack of knowledge about their non-visible genitalia made the tampon seem foreign and threatening.

When disposable pads and tampons became popular, they had two fundamental impacts for bio-women. First, they offered modernity-a new, practical, and hygienic way for bio-women to manage menstrual fluids. For the poorest white American women, African Americans, and immigrants, they represented a way to access the American way of life. In Argentina, low-income women accessed these products years later than the middle class, both for economic and symbolic reasons. Middle-class Argentine women, on the other hand, saw pads and tampons as a way of aligning with the prototype of modern women, specifically from countries such as the United States. The industry tapped into this aspiration by marketing disposable products as the antithesis of cultural and economic backwardness. Second, these products 
enabled women to mask and discard their menstrual blood, which also distanced them from their bodies. This led to some alienation of the body itself, even as it greatly eased menstrual management and the tension associated with hiding something seen as culturally disgusting.

So, if the disposable products were associated with women's liberation, what were women liberated from? In short, the technologies of "feminine protection" liberated women from a menstrual body that symbolized something shameful and uncontrollable - a body that could leave them out of the ideal of social acceptability in the public world. However, they did not liberate themselves from the social meanings that, in much more subtle forms, continued to signify their menstrual bodies as something wretched and deplorable.

\section{Public Discourse on Menstruation: Advertising and Educational Materials}

This section uses ads and educational materials from the United States and Argentina between 1920 and 1980 to summarize two main concepts that the "Femcare" industry conveyed transnationally about menstrual bodies. The ads are particularly important, as they comprised the main public discourse about menstrual bodies ${ }^{5}$ and had to resonate with the then-current cultural meanings in each social context.

During the twentieth century, the Femcare industry promoted both positive and negative conceptions of the menstrual body. On the one hand, menstruation continued to be portrayed as a construct of an impolite femininity, and disposable products added a more efficient way to deny the body. This reinforced traditional gender narratives of the fictional feminine ideal and what was necessary to be desirable. Advertisements represented women as being able to "fix" their biological "problem" and be productive $24 / 7$ in the public domain, with all traces of the menstrual body (the look, smell, and noise of both the blood and the products) safely hidden. On the other hand, materials continued to present the menstrual body as something positive: a symbol of femininity (becoming a woman); a fertile body, ready to become pregnant (a mother) from menarche on. The negative conceptions appeared mainly in advertisements; the more positive ones were in educational materials targeted toward teenagers.

As mentioned previously, the first publicity campaign for Kotex pads used the discourse of patriotism to launch its brand to the US market (Vostral 2008; Sahlberg 2011). That first ad featured a nurse taking care of wounded American soldiers on the French battlefield with the line, "To save men's lives, science discovered Kotex." Without ever explicitly mentioning menstruation, the ad suggested the pads as protectors of vulnerable menstruating women, and connected that to the strong, patriotic soldiers who were wounded (Fig. 59.1). 


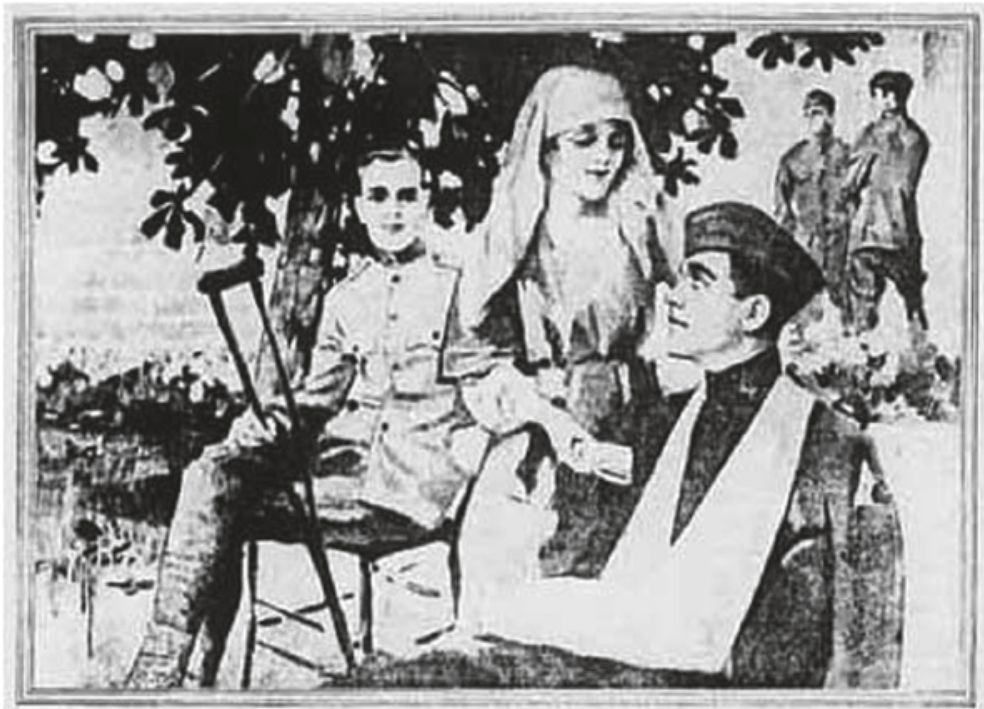

\section{To Save Men's Lives Science Discovered

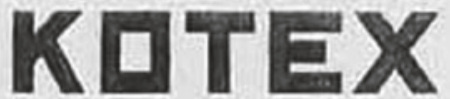

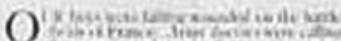

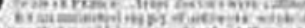

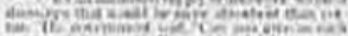

A War Emergency

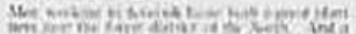

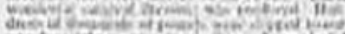

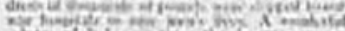

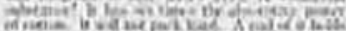

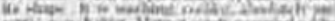
romation

Permanest Peace-Time Utility

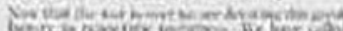

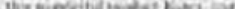

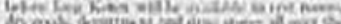

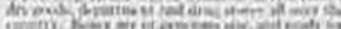

Cellucotton Products Company

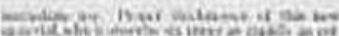

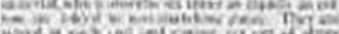

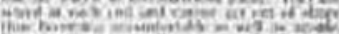

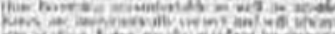
Q.

The Cot in Almont Nothing

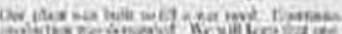
How

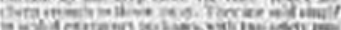

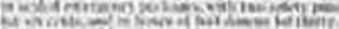

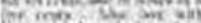

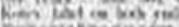

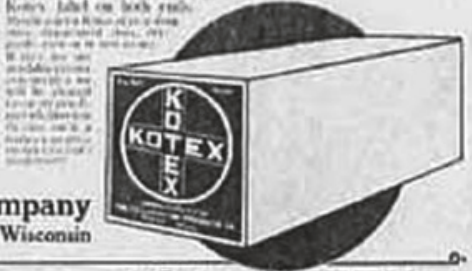

Divatione so Neeaah, Wiveonuin

Inexpensive, Comfortable. Hysienic and Safe - KUTEX

Fig. 59.1 Ladies Home Journal, 1921 (Credit: Copyright Kimberly-Clark Worldwide, Inc. Reprinted with permission)

From this foundational image, we can begin to reconstruct a story in which protection, hygiene, and liberation formed a semantic tripod throughout the twentieth century to advertise pads and tampons. Within this context, we find two "periods"- that is, period as in time, but also 
a metaphor that gave a social meaning to these technologies and, collaterally, reproduced feelings about the menstrual body. A first period, from the 1920s until around the 1950s, relied more heavily on concepts of hygiene and female protection; it extolled the hygienist discourse of the beginning of the century, mainly referring to a menstruating body as being simultaneously vulnerable and dangerous, as well as dirty. A second period, starting in the 1960s, aligned with the discourse of female liberation, freeing women from the internal enemy of menstruation in the form of "a mercantile feminism" (Goldman 1992). Like the earlier period, this second period highlighted the idea of a menstruating body as being vulnerable/dangerous, but this era also capitalized on the concept of menstruation as oppressive.

Educational materials focused on the idea of "becoming a young lady" through menarche. That involved (1) introducing a gender pedagogy of different bodily practices; $(2)$ promoting the idea that femininity demanded that menstruation be concealed; and (3) reinforcing the ideal that maternity was every woman's correct and natural destiny. This mainstream explanation of menstruation as "the preparation to become a mother" never questioned whether a bio-woman wanted to become one and, as Emily Martin ([1987] 2001) showed, reproduced gender stereotypes in their explanation of how procreation works (a passive egg that is conquered by an active sperm). Elsewhere, I discuss in more detail how this process unfolded in the United States and Argentina (Tarzibachi 2017). Many of these concepts are still embodied in descriptions that essentialize womanhood through the biological processes of menstruation and reproduction.

\section{Global Fluxes, in Numbers: The Femcare Industry in Las Americas Today}

Today, the Femcare or "sanitary protection" sector is second only to the diaper market in the global market for disposable hygienic products (Euromonitor International 2016a). In 2018, its global performance was around \$95 billion USD, with the United States and China being the two largest markets (Euromonitor International 2016a). This sector is expected to continue expanding, mainly due to the growth of emerging economies and "population changes and social and cultural shifts that influence women's lifestyles" (Euromonitor International 2018). However, the industry is already considering some threats to its market: reusable products, the increasing use of contraceptives that suppress menstrual bleeding, and rising global rates of obesity (which can change or stop periods) (Euromonitor International 2018).

Procter \& Gamble Co., Kimberly-Clark Corp., and Johnson \& Johnson Inc., have developed the biggest multinational operations in this sector (Bobel 2010; Euromonitor International 2016a). Disposable pads are the main product sold globally, with nearly 10 times the total sales of tampons, and pads with wings lead in terms of total sales and growth (Euromonitor 
International 2018). In 2015, global sales by product were distributed as follows: pads, $\$ 22.23$ billion; tampons, $\$ 2.84$ billion; and daily protectors $\$ 4.45$ billion (Euromonitor International 2016a). Tampon consumption varies widely. It is significantly lower in Latin America, the Middle East, Africa, and the Asian Pacific compared to North America, Australasia, and Western Europe (Euromonitor International 2016a).

Several factors explain this disparity. Given the higher cost of tampons compared to pads, they are easier to market in high-income countries. However, other societal factors seem to contribute to this uneven pattern of consumption. As discussed in earlier sections, there are often significant concerns related to sexuality, including loss of virginity, encouraging masturbation or promiscuity, and lack of knowledge about the body. Therefore, in cultures that place high symbolic value on virginity, closely regulate women's sexuality, and/or lack comprehensive sex education, there may be significant resistance to tampon use. Euromonitor International (2016a) identified several of these factors as barriers to tampon consumption at the global level. Additionally, women with a higher education-especially those who remember the 1970s and 1980s - are concerned about TSS, which made the news in the United States at about the same time that tampons began advertising in Latin America. More recently, the famous case of model Lauren Wasser, who had both legs amputated because of TSS, has renewed those fears (Bever 2017).

The following table summarizes the current state of the Femcare market in Las Americas. For each of the nine reference countries in that region, it illustrates the companies that dominate the market, product sales, projected growth, and the type of product most consumed (Table 59.1).

\section{United States}

Pads and tampons are consumed evenly (Euromonitor International 2016b). Of tampons sold in the United States, those with an applicator are by far the biggest sellers. Tampax continues to dominate. This is completely different from the situation in Argentina, where, since the launch of tampons in the late 1970s, its most economical version-without an applicator-has led sales.

\section{Argentina}

Given the economic crisis in Argentina, the volume of menstrual management product sales has decreased, especially among lower-income consumers (Euromonitor International 2016c). Disposable pads continue to be the most-consumed menstrual management product in Argentina; tampon usage was never significant. 


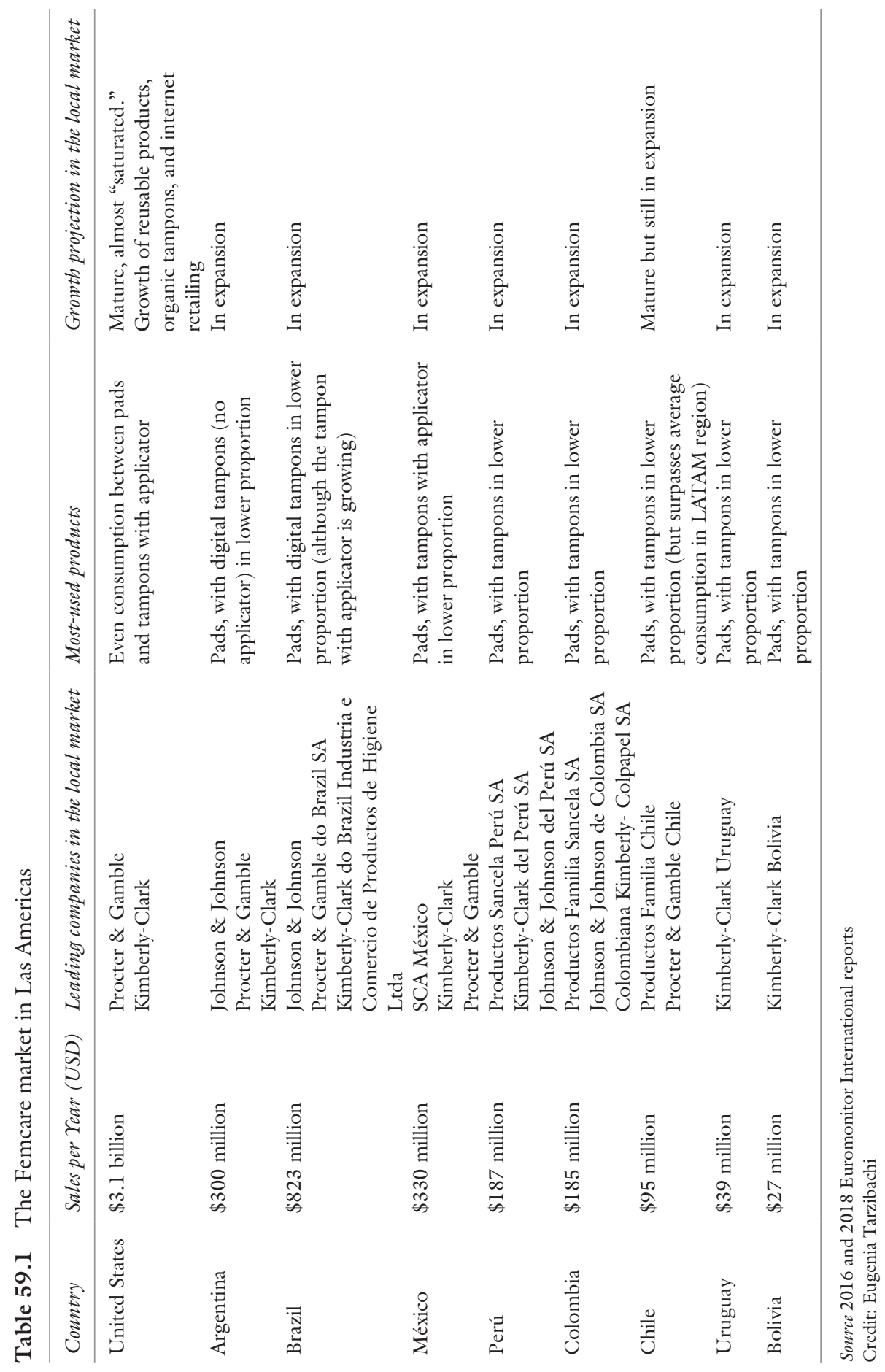




\begin{abstract}
Brazil
"Hygiene protection" product sales are higher in Brazil than in other Latin American countries, but remain significantly lower than in the United States and Europe (Euromonitor International 2016g, 1). The frequency of use differs widely between the upper-middle socioeconomic sectors (which resemble North America and Europe) and low-income sectors (which are far below the national average). The most-consumed product in Brazil is the pad. Tampons are two or three times more expensive than a standard pad, and marketing strategies for tampons focus on women of higher socioeconomic strata. The digital tampon is dominant, although those with applicators are slowly gaining, with a $30 \%$ market share. Global companies have an $85 \%$ share of the main market. Given the economic crisis in Brazil, annual growth of the local market has slowed, although some growth is still expected.
\end{abstract}

\title{
Mexico
}

Products are very segmented by social strata in Mexico (Euromonitor International 2016d). There are still rural communities where disposable products are not available, and women use rags that they wash and reuse. Marketing targets low-income women to increase per capita consumption. Digital tampons are no longer consumed; they are considered difficult to use and less hygienic, and they face more resistance than tampons with an applicator.

\section{Peru}

Sales in Peru registered a record growth of $9 \%$ in 2015, due to reduced poverty and increased purchasing power of the population (Euromonitor International 2016f). Pads are the best-selling product of the category, but the penetration of pads is only $70 \%$ in urban areas and $30 \%$ in rural areas. The tampon represents only $1 \%$ of Femcare sales, and $65 \%$ of those sold are tampons with applicators. Barriers to tampon use include fears about possible infections and the pull of traditional knowledge of Peruvian women, although there is greater openness among younger generations, particularly among 22 - to 40-year olds with middle to high income (Euromonitor International $2016 f, 1)$.

\section{Colombia}

National companies, such as Produsa SA with its Ellas brand, have small, regional distribution in the eastern part of the country, while multinationals have nationwide distribution (Euromonitor International 2016e). There are no specified cultural or religious factors that discourage the consumption of Femcare products; however, the tampon is still rejected. 


\section{Chile}

Sales are expected to hit 70 billion Chilean pesos in 2020 (Euromonitor International 2016h). Tampon use is low, as in the rest of Latin America, although it exceeds the average for that region. Sales are mainly seasonal, with peaks in the summer. The pad is the most-used product, and consumers indicate that the quality is markedly superior to pads in the rest of Latin America.

\section{Uruguay}

Tampons are not widely accepted in Uruguay. The women who use them are those with higher educational levels and greater purchasing power, and they prefer digital tampons to those with applicators. Women from lower income and educational backgrounds refer to powerful myths about tampons, and many consider them dangerous. Cotton and fabrics are still used by low-income women, especially those in rural areas. This is so despite the fact that low-cost brands are offered by several companies (Euromonitor International 2016j).

\section{Bolivia}

The pad is the most-consumed product in Bolivia, particularly the standard pad with wings. According to market research, there are no religious or traditional barriers to the tampon, but women prefer pads because of their lower cost and because they are unaware of the tampon's benefits (Euromonitor International 2016i, 2). A tampon with an applicator wasn't introduced in Bolivia until 2015. Cotton and rags are still used in remote rural areas, although expanded penetration and lower-cost products are reducing these traditional approaches. However, in some rural areas the intense taboo surrounding menstruation increases women's comfort with disposable products.

\section{Challenging the Legitimate Meanings of Menstruation: Menstrual Management and the Menstrual Taboo in the Twenty-First Century}

Today, the Femcare industry fosters very different discussions of the menstrual body than were prevalent during the twentieth century. Much of this is due to criticism the industry has received for practices-like showing blue liquids as a substitute for blood-that reproduce the menstrual taboo. "Female empowerment" is the new signifier, although it is sometimes used very conservatively, in ways that do not significantly challenge existing menstrual taboos. For example, the well-known campaign "Like a girl," features a politically palatable message of empowerment, but without going as far as showing menstrual blood. Perhaps the most revolutionary piece that has come out has been Libresse brand's Blood Normalo (2018). This ad earned the Glass Lion 
for Change Grand Prix on the final night of the Cannes Lions International Festival of Creativity. Johnson \& Johnson is now wading into these waters in Argentina and other Latin American markets by showing a red liquid for the first time in the history of its advertising there. The commercial Siempre Libre, Siempre Juntas ${ }^{7}$ (2018) is an example.

Further, the Femcare industry is no longer the dominant or only source of public discussion of menstruation, particularly in countries where the industry did not make inroads in the past century. A different type of intervention has been trending in these countries: efforts by international organizations focused on menstrual hygiene management to advocate for access to menstrual management products. The menstrual discourses promoted by menstrual hygiene efforts have been carefully reviewed by Bobel (2019). Another central actor is the pharmaceutical industry, which offers contraceptive methods that suppress menstruation (Sanabria 2016). Discussion of these technologies tends to portray menstruation as a useless physiological process that may even be dangerous for a woman's health. Competing discourses arise from small companies that produce menstrual cups, panties with pads, or reusable pads. These tend to encourage environmental sustainability and promote positive connotations that can reconnect women with the experience of menstruation-for example, Mother Earth, the different phases of the moon, the cyclic nature of menstruation. However, while some of these reusable technologies have new designs, many tend to evoke those used by the grandmothers of the Argentinian women interviewed, who regarded this form of menstrual management as culturally backward. Other small and little-known producers offer still more innovations, such as the vibrating tampon (a tampon with a vibrator inside that can be activated by women when they experience menstrual cramps).

These examples illustrate the varied approaches to the menstrual body taken by Femcare producers and others in the world of menstrual management. Some promise to protect bio-women from their own blood with disposable pads and tampons; others want women to connect with the benefits of menstruation as a way to promote social causes, such as environmental care. And others seek to suppress the menstrual cycle altogether, splitting a powerful cultural association between femininity and menstruation.

Menstrual activism is also challenging the meanings attached to menstruation. Artists and activists have transmuted the blood that for centuries was mere waste into products that can be, for many, disgusting: Art and facial masks made with menstrual blood are just two examples. The taboo of menstruation is being denounced even in high-visibility institutions such as the Oscar Awards, which in 2019 gave the Best Documentary (Short Subject) award to Period. End of sentence. And a new menstrual emoji brings representations of menstruation further into the mainstream. Yet research shows that the stigma of menstruation, which many think is a thing of the past, continues to unfold. Studies show how menstruation and menstrual products generate health risks, private costs absorbed by women, and environmental 
waste. The issue of sustainability is a double-edged sword: it can be used to individually blame menstruators for harming the planet, without challenging the cultural norms that require them to conceal their menstruation. Finally, research can reveal the multiple areas in which the topic of menstruation has been neglected, particularly in economic, environmental, gender, and reproductive and sexual health agendas. This is especially true for policies that address sexual education for children and adolescents.

These different discourses, and the ways they are antagonistic to each other, demonstrate how the meaning of the menstrual body is currently in dispute. Economic and other political interests are in conflict to define and control the symbolic power of menstruation. Some of these battles are driven by economic interests that have little concern for the dignity of menstruating people, while others aim to offer menstruators other modes of existence than dejection and shame. As more interests come into the arena-the Femcare industry, NGOs, activists, environmentalists-the result is that they often operate on the menstrual body as a battlefield.

\section{Notes}

1. Michael Foucault defined a disciplinary practice as a way of subjecting the body to a process of constant surveillance and examination that enables a continuous and pervasive control of individual behavior. In this case, it can be applied to the social construction of femininity (Foucault 1977, 138-39). Perpetual surveillance is internalized by individuals to produce the kind of self-awareness in relation to a social ideal of normality that defines the modern subject.

2. Femininity, here, is understood as a performance (Butler [1993] 2002), an artifice (Bartky 1990).

3. I follow Paul Preciado (2008) in using the term bio-women to avoid essentializing the category of women in a way that equates it with what our culture considers the female human biological body. Similarly, "menstrual bodies" is used as a neutral term that is meant to include menstruators with diverse gender identities.

4. My research in Argentina focuses on the generation that lived through the seventies as young women. This decade saw the introduction of the tampon, the last new "feminine protection" technology of the century, at the same time that disposable pads and disposable diapers became widely available. These effective, disposable products alleviated some of the physical and emotional work that was culturally assigned to women (for example, changing and laundering cloths for reuse and the emotional labor of masking menstruation). While they eased the burden of the tasks imposed on bio-women and were associated with women's liberation, they did not affect the dominant gendered narratives around what women should do and feel in order for their bodies to be considered socially acceptable.

5. You can find further discussion of the advertisements in each country, with a focus on their contextual particularities, in Chapter 3 of my book Cosa de Mujeres: Menstruacion, Genero y Poder (Tarzibachi 2017) and my conference at the Library of Congress of the United States in 2016 (https://www.loc.gov/ today $/$ cyberlc/feature_wdesc.php?rec=7642). 
6. https://www.youtube.com/watch?v=lm8vCCBaeQw.

7. https://www.jnjarg.com/siempre-libre/siempre-juntas.

\section{REFERENCES}

Bartky, Sandra. 1990. Femininity and Domination: Studies in the Phenomenology of Oppression. New York: Routledge.

Bever, Lindsey. 2017. "This Model Lost Her Leg Because of Toxic Shock Syndrome: Here's What She Wants You to Know.” The Washington Post, December 19, 2017. https://www.washingtonpost.com/news/to-your-health/wp/2017/12/19/ this-model-lost-a-leg-because-of-an-infection-from-tampons-heres-what-she-wantsyou-to-know/?noredirect $=$ on.

Bobel, Chris. 2010. New Blood: Third Wave Feminism and the Politics of Menstruation. London: Rutgers University Press.

- 2019. The Managed Body: Developing Girls and Menstrual Health in the Global South. Boston, MA: Palgrave Macmillan.

Brumberg, Joan J. 1997. The Body Project: An Intimate History of American Girls. New York: Random House.

- 1999. "'Something Happens to Girls.' Menarche and the Emergence of the Modern American Hygiene Imperative." In Women and Health in America, edited by Judith Leavitt. Wisconsin: University of Wisconsin Press.

Butler, Judith. [1993] 2002. Cuerpos que importan. Sobre los limites discursivos del sexo. Buenos Aires: Paidós.

Cosse, Isabella. 2009. "Los nuevos prototipos femeninos de los años 60 y 70: de la mujer doméstica a la joven liberada” En AA.VV. al cuidado de Andrea Andujar, Débora D’Antonio, Fernanda Gil Lozano, Karim Grammático y María Laura Rosa, De minifaldas, militancias y revoluciones. Exploraciones sobre los 70 en Argentina. Buenos Aires, Ediciones Luxemburgo.

- 2014. "Mafalda: Middle Class, Everyday Life, and Politics in Argentina, 1964-1973." Hispanic American Historical Review 94 (1): 35-77.

Euromonitor International. 2016a. "Sanitary Protection: Evolving Category in the Changing World of Womanhood." June 2016.

- 2016b. "Sanitary Protection in the US," June 2016.

- 2016c. "Sanitary Protection in Argentina," March 2016.

- 2016d. "Sanitary Protection in México," April 2016.

- 2016e. "Sanitary Protection in Colombia," March 2016.

- 2016f. "Sanitary Protection in Perú," March 2016.

- 2016g. "Sanitary Protection in Brazil," April 2016.

. 2016h. "Sanitary Protection in Chile," March 2016.

- 2016i. "Sanitary Protection in Bolivia," March 2016.

_. 2016j. "Sanitary Protection in Uruguay." April 2016.

- 2018. "STRATEGY BRIEFING." Feminine Care Industry Global Outlook.

Foucault, Michel. 1977. Discipline and Punish: The Birth of the Prison. Translated by A. Sheridan. Harmondsworth: Peregrine.

Freidenfelds, Lara. 2009. The Modern Period: Menstruation in Twentieth Century America. Baltimore: John Hopkins University Press.

Goldman, R. 1992. Reading Ads Socially. NY: Routledge.

Hasson, Katie Ann. 2016. "Not a 'Real' Period? Social and Material Constructions of Menstruation." Gender \& Society 30 (6): 958-83. https://doi.org/10.1177/ 0891243216672662 . 
Heinrich, T., and B. Batchelor. 2004. Kotex, Kleenex, Huggies: Kimberly-Clark and the Consumer Revolution in American Business. Columbus, OH: Ohio State University. Kissling, Elizabeth. 2006. Capitalizing on the Curse: The Business of Menstruation. London: Lynne Reinner Publishers.

Manzano, V. 2009. "The Blue Jean Generation: Youth, Gender, and Sexuality in Buenos Aires, 1958-1975." Journal of Social History 42 (3): 657-76.

- 2010. "Juventud y modernización sociocultural en Argentina." Desarrollo Económico 50 (199): 363-90.

Martin, Emily. [1987] 2001. The Woman in the Body: A Cultural Analysis of Reproduction. Boston: Beacon Press.

Preciado, B. 2008. Testo Yonqui. Madrid: Espasa-Calpe.

Sahlberg, J. 2011. "Kotex: An Early 20th Century Demonstration of Media Campaigns Addressing Stigma." The Yale Historical Review I (5): 33-43.

Sanabria, Emilia. 2016. Plastic Bodies: Sex Hormones and Menstrual Suppression in Brazil. Durham: Duke University Press.

Siemaszcko, K., J. M. Mendez Ribas, B. Warman, N. Pereyra Pachecho, N. Macagno, and R. Nicholson. 1980. "Anticoncepción en adolescencia (I)." Obstetricia y Ginecología Latino Americana 38, Año 38, julio agosto: 221-29.

Tarzibachi, Eugenia. 2017. Cosa de Mujeres. Menstruación, Genero y Poder. Buenos Aires: Sudamericana.

Vostral, Sharra. 2008. Under Wraps: A History of Menstrual Hygiene Technology. Plymouth: Lexington Books.

- 2010. "Tampons. Re-scripting Technologies as Feminist." In Feminist Technology, edited by Linda Layne, Sharra Vostral, and Kate Boyer. Chicago: University of Illinois Press.

- 2011. "Rely and Toxic Shock Syndrome: A Technological Health Crisis." Yale Journal of Biology and Medicine 84: 447-59.

Open Access This chapter is licensed under the terms of the Creative Commons Attribution 4.0 International License (http://creativecommons.org/licenses/ by/4.0/), which permits use, sharing, adaptation, distribution and reproduction in any medium or format, as long as you give appropriate credit to the original author(s) and the source, provide a link to the Creative Commons license and indicate if changes were made.

The images or other third party material in this chapter are included in the chapter's Creative Commons license, unless indicated otherwise in a credit line to the material. If material is not included in the chapter's Creative Commons license and your intended use is not permitted by statutory regulation or exceeds the permitted use, you will need to obtain permission directly from the copyright holder. 